\title{
MRI-derived cardiac mechanical dispersion for risk stratification in patients with ischemic cardiomyopathy: a preliminary study
}

\author{
Elisabeth H Paiman ${ }^{1 *}$, Qian Tao ${ }^{1}$, Alexander F Androulakis², Katja Zeppenfeld², Hildo J Lamb', \\ Rob J van der Geest ${ }^{1}$
}

From 19th Annual SCMR Scientific Sessions

Los Angeles, CA, USA. 27-30 January 2016

\section{Background}

Prediction of ventricular arrhythmias (VA) after myocardial infarction remains challenging. There has been evidence that strain echocardiography can improve risk prediction. Patients with a high degree of contraction inhomogeneity are thought to be at increased risk of arrhythmic events. Mechanical dispersion may be due to inhomogeneous electrical activation and the resulting dyssynchronous contraction may further promote pathological remodelling. Aim of this study was to quantify mechanical dispersion, based on radial wall motion tracking from short-axis cine MRI, and its association with VAs and mortality.

\section{Methods}

A total of 136 patients (age $63 \pm 11$ years) with ischemic cardiomyopathy underwent cardiac MRI prior to implantable cardioverter-defibrillator (ICD) placement. Outcome measure was defined as the composite of appropriate ICD therapy and all-cause mortality. On short-axis cine MRI, endo- and epicardial contours were semi-automatically tracked over the complete cardiac cycle. For each slice, radial wall motion was derived for 20 radial segments from the displacement of the endocardial contours, relative to the center of the epicardial contours. Radial wall motion curves were filtered by means of a Hanning window and clustered according to similarity of contraction patterns, to constitute a patient-specific reference curve. Delay time between the radial wall motion curve for each segment and the reference curve was calculated by cross correlation as previously described by Suever et al. [1]. Mechanical dispersion was quantified as the standard deviation of the delay time for all segments.

\section{Results}

Median follow-up was 50 months (interquartile range 36-67 months). A total of 43 patients (32\%) received appropriate ICD therapy and 21 (15\%) patients died, without receiving ICD therapy before death. Univariate Cox proportional hazard analysis resulted in a hazard ratio (HR) of 1.09 per $10 \mathrm{~ms}$ increase of mechanical dispersion, which, however, was not statistically significant (95\% CI: HR 0.99-1.20/10 ms; $\mathrm{p}=0.07$ ).

Table 1 Baseline MRI variables

\begin{tabular}{|c|c|c|c|c|}
\hline & $\begin{array}{l}\text { Total population } \\
(n=136)\end{array}$ & $\begin{array}{l}\text { No appropriate ICD therapy or all-cause } \\
\text { mortality }(n=72)\end{array}$ & $\begin{array}{c}\text { Appropriate ICD therapy or all-cause } \\
\text { mortality }(n=64)\end{array}$ & $\begin{array}{c}P \\
\text { value }\end{array}$ \\
\hline LVEF, \% & $30 \pm 9$ & $31 \pm 9$ & $28 \pm 9$ & 0.03 \\
\hline $\begin{array}{l}\text { Mechanical } \\
\text { dispersion, ms }\end{array}$ & $61 \pm 25$ & $58 \pm 23$ & $65 \pm 26$ & 0.1 \\
\hline
\end{tabular}

${ }^{1}$ Department of Radiology, Leiden University Medical Center, Leiden,

Netherlands

Full list of author information is available at the end of the article 


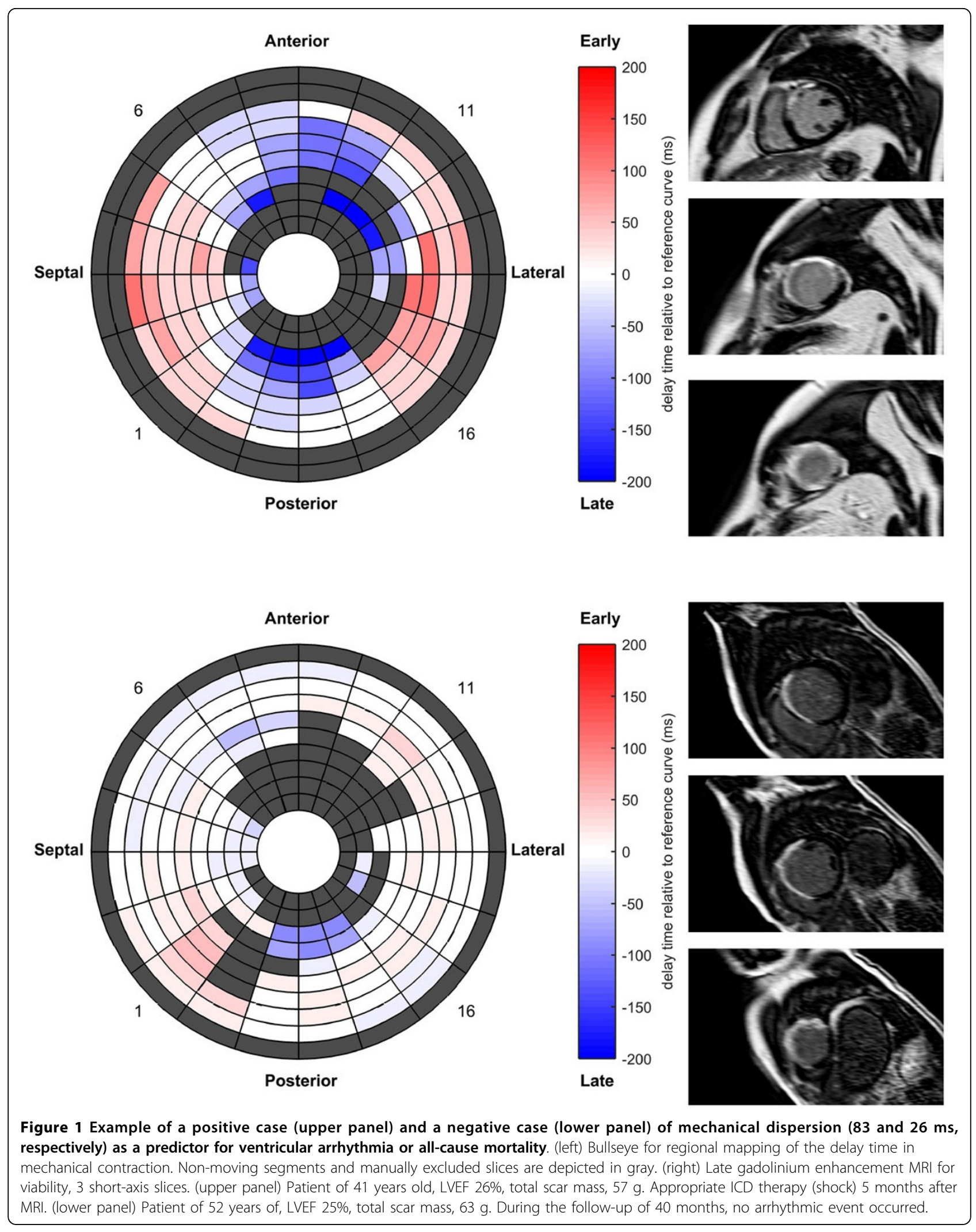




\section{Conclusions}

In this preliminary study, post-infarction patients with increased mechanical dispersion as computed from cineMRI have demonstrated a tendency, although not statistically significant, towards experiencing spontaneous VA or all-cause mortality. Further investigations are necessary to understand the potential predictive value of this mechanical parameter, with differentiation of high/low ejection fraction levels, on a larger group of patients.

\section{Authors' details}

'Department of Radiology, Leiden University Medical Center, Leiden, Netherlands. ${ }^{2}$ Department of Cardiology, Leiden University Medical Center, Leiden, Netherlands.

Published: 27 January 2016

doi:10.1186/1532-429X-18-S1-P67

Cite this article as: Paiman et al:: MRI-derived cardiac mechanical dispersion for risk stratification in patients with ischemic

cardiomyopathy: a preliminary study. Journal of Cardiovascular Magnetic Resonance 2016 18(Suppl 1):P67.

Submit your next manuscript to BioMed Central and take full advantage of:

- Convenient online submission

- Thorough peer review

- No space constraints or color figure charges

- Immediate publication on acceptance

- Inclusion in PubMed, CAS, Scopus and Google Scholar

- Research which is freely available for redistribution

Submit your manuscript at www.biomedcentral.com/submit
C Biomed Central 